\title{
The Visualization Analysis of Human Resources in Science and Technology in Foreign Research Based on the Mapping Knowledge Domain
}

\author{
Hongjun Fang \\ Humanities and Sciences School, Dalian University of Technology \\ 2 Linggong Road, Dalian 116023, China \\ E-mail: hgthongjun@buu.edu.cn \\ Biochemical Engineering College, Beijing Union University \\ 18 Fatou Xili Sanqu, Chaoyang district, Beijing, 100023, China \\ E-mail: hgthongjun@buu.edu.cn \\ Yanjun Dai \\ Humanities and Sciences School, Dalian University of Technology \\ 2 Linggong Road, Dalian 116023, China \\ Tel:86-10-84706420 E-mail: daiyanjun@hotmail.com
}

This paper is a part of Beijing Education Commission's Social science project of study on the power relationship between Human Capital and realizing modernization lead in Beijing, the number of the project is SM200911417009

\begin{abstract}
According to the data provided by SSCI database, we use Cite Space software to map out the knowledge map of human resources in science and technology in foreign research from keywords, document co-citation, author co-citation and journal co-citation based on the basic principles of Scientometrics. The paper shows the foreign research fronts and hot spots of study on human resources in science and technology
\end{abstract}

Keywords: Human resources in science and technology, Mapping knowledge domain, Co- citation analysis

\section{Introduction}

At present, a lot of countries have a more and more profound understanding of the importance of human resources in science and technology (HRST). As the core of scientific and technological resources, HRST is the most innovative and revolutionary one and it supports the production, dissemination and application of a country's scientific and technological knowledge. HRST plays an important role for a country in promoting economic and social development. Therefore, all countries in the world have accelerated the study's pace and the progress of HRST to give effective guidance of HRST development and usage. As to the study of HRST, UNESCO, OECD, EU and other international organizations, experts and scholars all over the world have carried out extensive and in-depth research and achieved great research achievements in recent years.

\section{Data Sources and Research Methods}

All of the data used in this article are collected from the Social Science Citation Index (SSCI) database of ISI of the United States. In accordance with the HRST classification criteria of OECD and EU's "HRST Handbook" about science and technology human resources in two dimensions(qualification and education dimension, combining with the actual situation of current international study of HRST,we used "Human Resource in Science and Technology" "Human Capital in Science and Technology" "Technical staff" "R\&D Staff" as keywords in title to search literature. After the strict cleaned and screened, a total of 298 records are collected from 1998 to 2008. Each record includes author, institution, abstract, keywords, year, period (volumes) and references. In this paper, Cites pace mapping software are used to map the network and analyze the data.

In 2004, basing on the theory of citation analysis and application of Java language, Chaomei Chen, a Professor of Information Science and Technology College in Drexel University, developed Information Visualization-CiteSpace information visualization software. This software has become the most distinctive and influential visual information software in field of information analysis in the United States recently, CiteSpace visualization software is a network software of co-cited analysis and it provides a pathfinder network scaling map (PFNET). Through a rational threshold set of citation, co-citation and co-citation coefficient, it can draw more intuitive knowledge maps and is easy to understand. In this article, we combine quantitative analyze with qualitative analysis methods to carry out the research. By using the online version of CiteSpace (V.2.1) knowledge mapping analysis software, we set coefficient appropriate adjustments of three parameters $(\mathrm{C}, \mathrm{CC}, \mathrm{CCV})$ to carry out co-occurrence analysis of key 
words, analysis of co-citation documents, author co-citation and journal co-citation. Hot spots of a field of academic study or research can be found in analysis of the keywords map, and the transfer trends of researching hot spots may be found in it; key documents and the evolution driving force of disciplines or research field can be found by analysis of co-citation documents map; the important core authors and their academic relation in a subject or an research field can be found by analysis of author co-citation map. In this article, CiteSpace software is used to draw out the knowledge map of research field of foreign HRST to analyze the study situation of foreign HRST.

\section{Analysis of Data Result}

\subsection{Analysis of Keywords Co-Occurrence Map}

Insert Figure 1 Here

\section{Insert Table 1 Here}

Through analysis of word co-occurrence frequency in the Table 2.1, "human capital" has become a hotspot in research of foreign HRST and it is also an important study of the general human resources management in 1960's, the complete human capital theory are created by Theodore. Schultz and improved by Gary Becker and Jacob mincer etc from different angles. In order to make a breakthrough of the shackles of traditional theory in which the capital is only the physical capital, We use human capital theory to study economic theory and practice from a new perspective. Therefore, the human capital theory was an important aspect of the international HRST study field. Secondly, "innovation" is in the second place. At present, all countries in the world have known the importance of science and technology innovation with more and more profound understanding. As the core of scientific and technological resources, HRST has obvious innovative features. The quantity and quality of HRST is a basis for national innovation capacity and it determines the level and performance of the country's innovation fundamentally and plays an important role in promoting economic and social development. Schumpeter, Walter Rostow and NSF(S. Myers, D. G. Marquis) began to study technological change and innovation in 1912. The theoretical study on innovation was further deeper and its system theory began to take shape later. "Performance" is in the third place. Performance is the desired result of scientific and technological innovation of HRST for a country or an organization and it is an effective output of a country or an organization to achieve its objectives at different levels. The study on the performance of HRST abroad is mainly embodied in macro and micro aspects. Effective development and utilization of HRST are discussed by foreign scholars in recent years. In addition, the study of "knowledge" "technology" "growth" "management" "system" are also hot spots in this field. The study of "knowledge" and "strategy" are more important burst terms in this knowledge map and the frequency of their emergence have taken great changes significantly.

\subsection{Analysis of Document Co-citation Map}

\section{Insert Figure 2 Here}

From the view of being cited, Mark $\bullet$ A $\bullet$ Huselid is Rutgers University's professor and his article of "The impact of human resource management practices on turnover, productivity, and corporate financial performance" was published by "Academy of Management Journal" in 1995. This article has a great influence in this research area so its citation frequency is the highest. Huselid evaluated comprehensively the links between systems of high performance work practices and firm performance and analyzed human resource management practice's impact on turnover rate, productivity and the impact of the financial performance of organizations by using survey data and archival data. He found that high-performance human resource management practices had significant positive impact on organization performance. The article is an important guidance to explore the relationship between HRST management practice and organizational performance. Gary • Becker won the Nobel Prize in 1992, and his article of "Investment in human capital: a theoretical analysis" was published by "Journal of Political Economy" in 1962. The article's cited times are in the second place. The study of "human capital" is the classic one of Gary Becker's. In this article, He analyzed how to invest in human capital through the way of education, training and family etc. Nobel Committee regarded the study of human capital of Becker's as an important contribution to the development of economics and this shows that his theory of human capital has an important effect on the human capital investment research area of HRST. Coleman, J. S's "Social capital in the creation of human capital" was published by "The American Journal of Sociology" in 1988.In this article, Coleman stressed that human capital can be acquired through the social capital. Almeida. P \& Kogut. B's article of "Localization of knowledge and the mobility of engineers in regional networks" was published in 1999. They investigated the relationships between the mobility of major patent holders and the localization of technical knowledge through the analysis of the important semiconductor innovation patent citations. Analysis of statistical data about inter-firm patent holder's mobility and empirical research shows that inter-firm mobility of engineers has impacts on the local transfer of knowledge. As to the book of high-frequency cition, Schultz's book of "The Economic Value of Education" published in 1963 is more 
influential. The book shows that people invest in themselves in order to increase production capacity and consumption capacity and school education is the largest investment in human capital. This book is taken as an important guideline on theoretical research and practice management of investment in HRST. In addition, Bourdieu P's books of "The Forms of Capital, J. D. Richardson, Handbook of Theory and Research for the Sociology of Education"(1986)and "An Invitation to Reflective Sociology"(1992)have great influence in the area of the investment of HRST too. Literatures cited above reflect the major theoretical sources and important research content of foreign HRST's study, such as the form and structure of capital, investment of human capital, the economic value of education and HRM practices. This built a good foundation for the theory's study and management practice of HRST abroad.

Form the view of centrality of literatures, Nahapiet \& Ghoshal's article of "Social capital, intellectual capital, and the organizational advantage" was published by "Academy of Management Review" in 1998. The article's centrality is 0.13 and it is an important node in mapping knowledge domain. They studied social capital's mechanisms about intellectual capital,created a conceptual model and stressed that knowledge, information, technology and intellectual property that can be used to create wealth are integral elements of intellectual capital. Cohen \& Levinthal's article of "Absorptive capacity: a new perspective on learning and innovation" was published by "Administrative Science Quarterly" in 1990.This paper's centrality is 0.10 and it is an important node too. They made a more detailed explanation about absorptive capacity of organization and thought that $R \& D$ investment has a dual nature - R \&D investment income and technical opportunities conditions. They considered that the absorptive capacity of enterprises is the capacity of evaluation, digestion and application of new knowledge for commercial purposes and the absorptive capacity of organizations depends on the members' absorptive capacity of organizations".

\subsection{Analysis of Author Co-citation Map}

Insert Figure 3 Here

\section{Insert Table 2 Here}

Firstly, through analysis of the list 2.2 , the centrality of OECD is 0.30 and it is the most important node. OECD has played an important role of guidelines in HRST research field because the greatest impact and the most comprehensive literature is the OECD and EU's book of "Science and Technology Human Resources Manual" published in 1995 in the field of study on HRST's concepts, indicators and measurement methods. The handbook provides an authoritative interpretation of a qualified and professional standard of HRST, an analysis about HRST's definition, content, statistical indicators, the relative question, the international first classification system and measurement standards of HRST's statistical indicators. The handbook has become an important guidance standard and scientific foundation for the study of HRST's theoretical analysis and practice management. Secondly, the node's centrality of Bartel A.P is 0.22 . Barte , a professor of Columbia University in the United States, conducted a longitudinal survey of national youth and found that workers of manufacturing production Industry with a more rapid technological change are more likely to receive formal company training. He found that the low-skilled non-industrial workers can receive more training than higher skilled non-industrial workers obviously and the proportion of individuals was also increasing. In addition, he conducted a longitudinal survey of national old agedness and thought that technological changes that would affect the retirement decisions of older workers at the two aspects: one was that industrial workers would retire later if there was a positive correlation relationship between technological change and training in-service; the other is that it would enable older workers to retire early if the necessary training is an unattractive investment. He also analyzed the relationship between technological change and wage in different industry too. Grilliches put forward the complementariness between capital and skills in 1969 and thought that the complementariness of high-skilled labor and physical capital was stronger than that of low-skilled labor and physical capital. In other words, low-skilled labor was more easily replaced by physical capital. He made a detailed study on the related issues between R\&D and productivity growth in 1979 and investigated patent statistics regarded as economic indicators in 1990. Lucas R E is a visiting professor of the University of Chicago and a central figure of new classical macroeconomics. He won Nobel Prize in 1995. His article of "On the Mechanics of Economic development "has a great influence in the world. In particular, he stressed that human capital may be accumulated through education and the special human capital could be accumulated through "learning by doing". In addition, his book of "Why does not capital flow from rich countries to poor countries" are also influential.

In addition, Gary•Becker, Mark•Huselid, Bozeman, Cohen, Pfeffer and others are important figures in the research field of HRST. Huselid's book of "The HR scorecard: Linking people, strategy, and performance" and "The workforce scorecard: Managing human capital to execute strategy" have become international best-selling books;Schultz's book of "Capital Formation by Education" "Investment in Human Capital" and "The Economic 
Value of Education" have had a significant impact in the field too;Allen TJ proposed a well-known theory of "learning by doing" and the theory is an important complement to human capital theory. After 1980's, Romer, Lucas and others put forward the theory of "new growth" and they brought out the spill-over characteristics of human capital and proved that human capital was the source of economic growth.

\subsection{Analysis of Journal Co-citation Map}

\section{Insert Figure 4 Here}

\section{Insert Table 3 Here}

By analyzing the journals' central and cited times in the list2.3, the important core journals can be clearly found in the research field of HRST. These are "AM ECON REV" "ACAD MANAGE REV"“SCIENCE"“ORGAN SCI"“RES POLICY"“ACAD MANAGE J"“MANAGE SCI"“IEEE T ENG MANAGE" and so on. The study shows their important academic status in the field. In addition, through analysis of burst words in the map, the cited times of "HUMEN RESOURCE MANAG"“J MANAGE"“INT J TECHNOL MANAGE”“ACAD MANAGE REV"“'RES POLICY" took great changes. The United States, Britain, Canada, New Zealand, France and Italy are main countries to study HRST; Main research institutions are Georgia Institute of Technology, the University of Wisconsin, the University of California, Berkeley and University of Nottingham etc. The main areas of research are related to management science, economics, engineering, psychology, computer science, operations and management science and other fields.

\section{References}

Almeida P. Kogut, B. (1999). Localization of knowledge and the mobility of engineers in regional networks.Management Science, 7, 905-917

Becker G. S. (1962), Investment in human capital: a theoretical analysis. Journal of Political Economy,70 (5) pp. 2. $9-49$

China Science and Technology Association.(2008). The Report on Development of HRST in China .Beijing; China Sience and Technology Press.2

HOU Jianhua, CHEN Yue. (2007). Research on visualization of the evolution of strategic management Front. Studies in Science of Science, 6,16-17

Huselid M. A. (1995). The impact of human resource management practices on turnover productivity and corporate financial performance. Academy of Management Journal,38,635-672

Lucas R E,(1988). On the mechanics of economic development,Journal of Monetary Economics,.22,3-42.

ZHANG Ya-bin, ZENG Zheng. (2005). Comments on technical progress and R\&D investment theory in the theory of economic growth. Economy Review, 6

ZHAO Yupeng, LIU Zeyuan, XU Zhenliang. (2008). The analysis of research frontier and hot topics about Journal of Philosophy of Science that based on the mapping knowledge domain. Studies in Science of Science, 12,26,6

Table 1.Keywords High-frequency list

\begin{tabular}{|c|c|c|c|}
\hline Keywords & Frequency & Keywords & Frequency \\
\hline human capital & 26 & industry & 11 \\
\hline innovation & 20 & impact & 9 \\
\hline performance & 19 & firm & 9 \\
\hline knowledge & 15 & turnover & 9 \\
\hline technology & 14 & model & 9 \\
\hline growth & 13 & human resource manage & 8 \\
\hline system & 13 & firm performance & 7 \\
\hline science & 12 & strategy & 7 \\
\hline productivity & 12 & research \& Develop & \\
\hline management & 12 & organizations & \\
\hline
\end{tabular}


Table 2.Author Co-citation list

\begin{tabular}{|c|c|c|c|}
\hline Sequence & Centrality & Times cited & Author \\
\hline 1 & 0.30 & 11 & OECD \\
\hline 2 & 0.22 & 9 & BARTEL AP \\
\hline 3 & 0.20 & 11 & GRILICHES Z \\
\hline 4 & 0.18 & 14 & COHEN WM \\
\hline 5 & 0.16 & 11 & LUCAS RE \\
\hline 6 & 0.15 & 19 & BECKER GS \\
\hline 7 & 0.12 & 15 & BOZEMAN B \\
\hline 8 & 0.05 & 16 & HUSELID MA \\
\hline 9 & 0.05 & 11 & SNELL SA \\
\hline 10 & 0.03 & 13 & ALLEN TJ \\
\hline 11 & 0.03 & 12 & WRIGHT PM \\
\hline 12 & 0.01 & 13 & PFEFFER J \\
\hline
\end{tabular}

Table 3.Journal Co-citation list

\begin{tabular}{|c|c|c|c|}
\hline Sequence & Centrality & Times cited & Journal \\
\hline 1 & 0.26 & 45 & AM ECON REV \\
\hline 2 & 0.21 & 44 & ACAD MANAGE REV \\
\hline 3 & 0.20 & 13 & SCIENCE \\
\hline 4 & 0.11 & 33 & ORGAN SCI \\
\hline 5 & 0.10 & 34 & RES POLICY \\
\hline 6 & 0.09 & 37 & MANAGE SCI \\
\hline 7 & 0.09 & 27 & R\&D MANAGE \\
\hline 8 & 0.09 & 27 & J POLIT ECON \\
\hline 9 & 0.08 & 42 & ACAD MANAGE J \\
\hline 10 & 0.08 & 27 & IEEE T ENG MANAGE \\
\hline 11 & 0.06 & 34 & ADMIN SCI QUART \\
\hline 12 & 0.06 & 19 & INT J TECHNOL MANAGE \\
\hline 13 & 0.04 & 29 & HARVARD BUS REV \\
\hline 14 & 0.02 & 26 & J MANAGE \\
\hline 15 & 0.01 & 19 & HUMEN RESOURCE MANAG \\
\hline
\end{tabular}

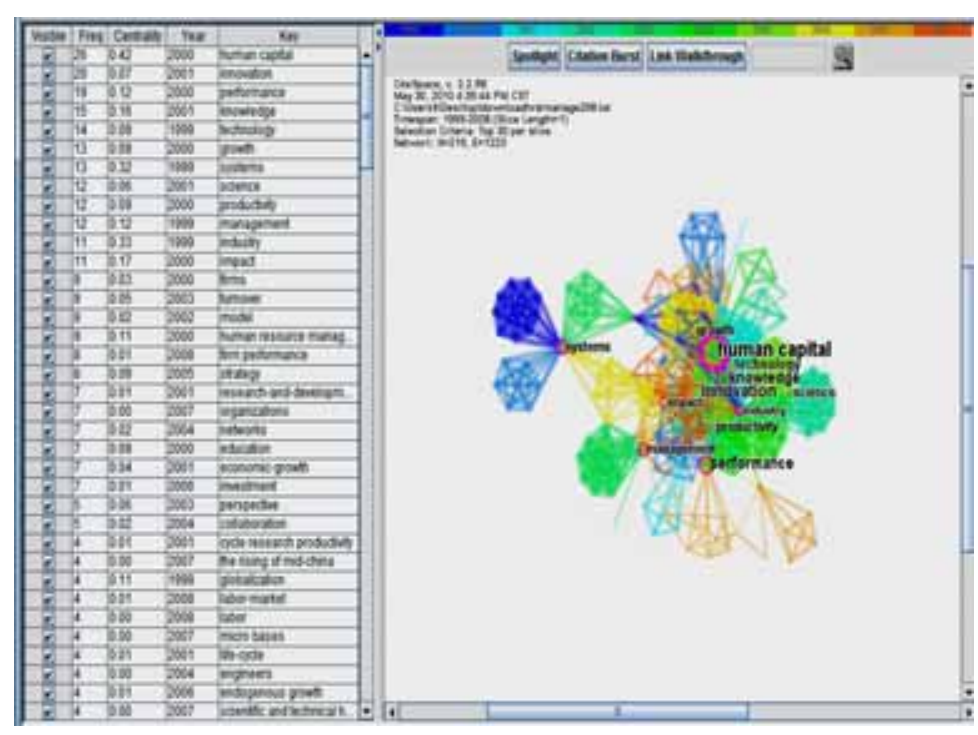

Figure1. Keywords Co-Occurrence Network Map 


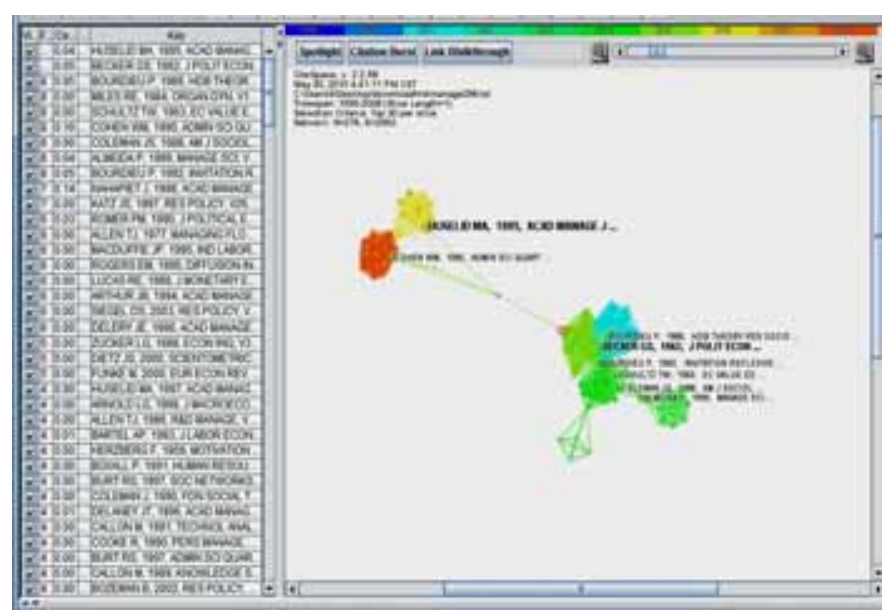

Figure 2.Document Co-citation Patterns of Network

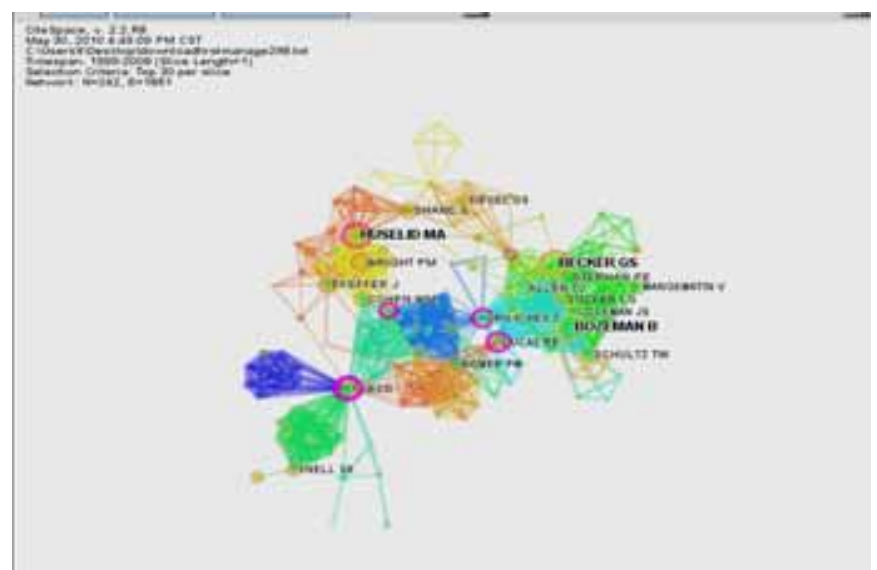

Figure 3.Author Co-citation Patterns of Network

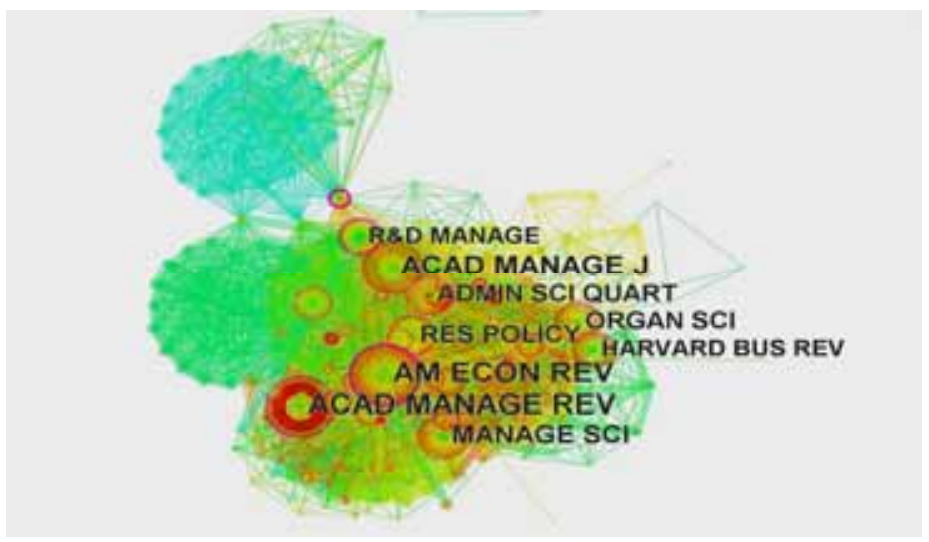

Figure 4.Journal Co-citation Patterns of Network 